Synthesis of Natural

\title{
Synthesis of (+)-Ophiobolin A
}

Products and

Potential Drugs

\section{Key words}

\section{Reformatsky} reaction

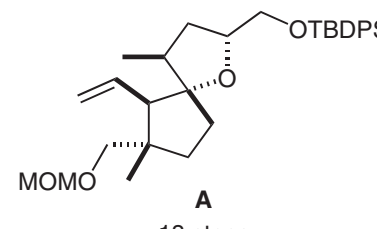

18 steps

Org. Lett. 2006

8, 2039

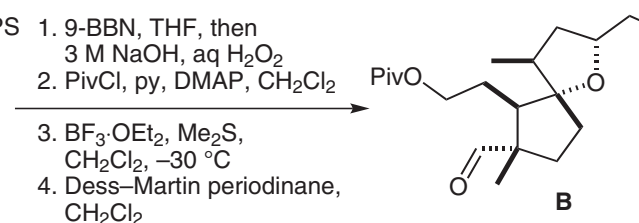

$\mathrm{CH}_{2} \mathrm{Cl}_{2}$

$86 \%$ over 4 steps

OtBdPs 1. C, $\mathrm{Ph}_{3} \mathrm{SnH}, \mathrm{Et}_{3} \mathrm{~B}, \mathrm{C}_{6} \mathrm{H}_{6}$ 2. Burgess reagent, $\mathrm{C}_{6} \mathrm{H}_{6}$ $83 \%$ over 2 steps
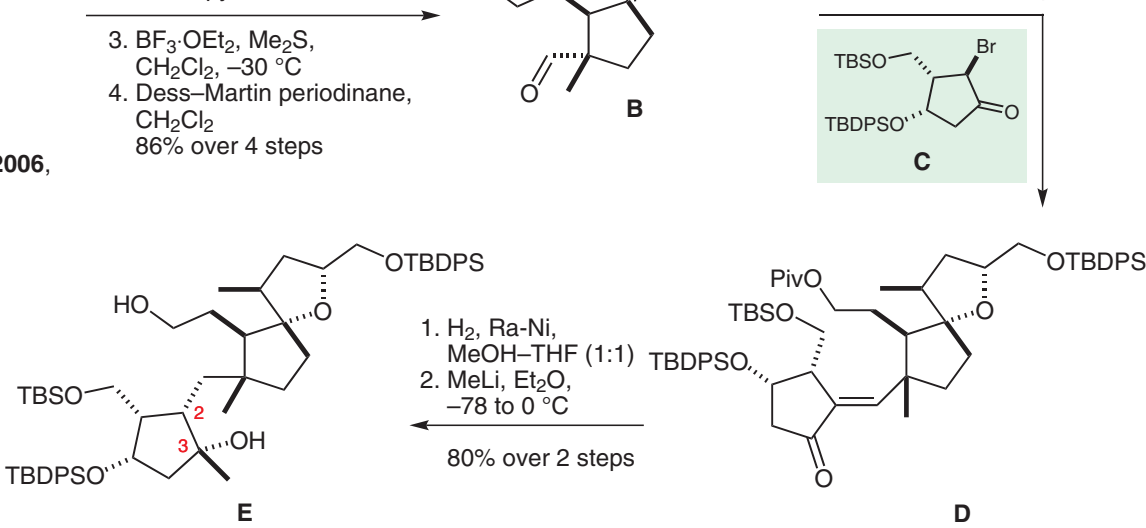

dr at C2 $=41:$

single diastereomer

at $\mathrm{C} 3$

7. TMSCl, imidazole, DMF $76 \%$ over 7 steps

1. Comins' reagent, KHMDS, $\mathrm{THF},-78^{\circ} \mathrm{C}$

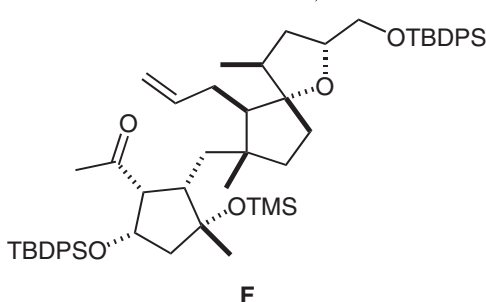

2. $\mathrm{Pd}\left(\mathrm{PPh}_{3}\right)_{4}, \mathrm{Et}_{3} \mathrm{~N}, \mathrm{CO}(1 \mathrm{~atm})$,

$\mathrm{MeOH}-\mathrm{PhMe}(20: 1), 50^{\circ} \mathrm{C}$

3. DIBAL-H, hexane, $-78^{\circ} \mathrm{C}$

4. $\mathrm{PivCl}$, py, DMAP, $\mathrm{CH}_{2} \mathrm{Cl}_{2}$

5. TBAF, THF

6. TBSCI, DIPEA, DMAP, $\mathrm{CH}_{2} \mathrm{Cl}_{2}$

7. $\mathrm{BnBr}, \mathrm{NaH}, \mathrm{DMF}, \mathrm{O}^{\circ} \mathrm{C}$

8. DIBAL-H, hexane, $-78^{\circ} \mathrm{C}$

$36 \%$ over 8 steps

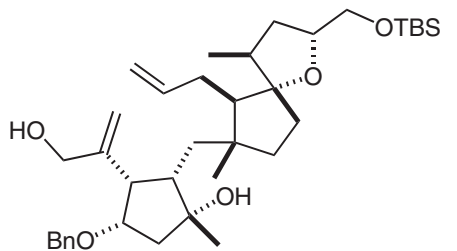

G

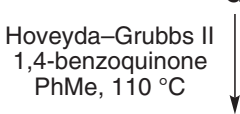

$\mathrm{BnBr}, \mathrm{NaH}, \mathrm{DMF}, 0^{\circ} \mathrm{C}$

2. PPTS, EtOH

3. $(\mathrm{COCl})_{2}, \mathrm{DMSO}, \mathrm{Et}_{3} \mathrm{~N}$,

$\mathrm{CH}_{2} \mathrm{Cl}_{2},-78{ }^{\circ} \mathrm{C}$

4. $\mathrm{Me}_{2} \mathrm{CHP}^{+} \mathrm{Ph}_{3} l^{-}, n$-BuLi

5. Li, naphthalene, THF, $-30^{\circ} \mathrm{C}$

6. $(\mathrm{COCl})_{2}, \mathrm{DMSO}, \mathrm{Et}_{3} \mathrm{~N}$

$\mathrm{CH}_{2} \mathrm{Cl}_{2},-78{ }^{\circ} \mathrm{C}$

$33 \%$ from $\mathbf{G}$



sesterterpenes

ring-closing

metathesis

Significance: $(+)$-Ophiobolin is a naturally occurring sesterterpene isolated from the pathogenic plant fungus Ophiobolus miyabeanus in 1958. It exhibits bioactivity against a range of nematodes, fungi, and bacteria. Herein, the first total synthesis of (+)-ophiobolin is reported.

SYNFACTS Contributors: Steven V. Ley, Sean Newton

Synfacts 2011, 12, 1265-1265 Published online: 18.11.2011

DoI: 10.1055/s-0031-1289342; Reg-No.: N06911SF
Comment: This synthesis utilizes Utimoto's conditions (Tetrahedron Lett. 1988, 29, 1041) for the Reformatsky-type coupling of $\alpha$-bromo ketone $\mathbf{C}$ and aldehyde $\mathbf{B}$ in high yield. Stereoselective hydrogenation and methyl addition are utilized to install the stereocenters at C2 and C3 with excellent selectivity. A ring-closing metathesis is used to form the unsaturated eight-membered ring. 